\title{
Innovation in the digital economy: a broader view of its scope, antecedents, and consequences
}

\author{
Alina Sorescu ${ }^{1} \cdot$ Martin Schreier $^{2}$ \\ Published online: 3 June 2021 \\ (C) Academy of Marketing Science 2021
}

In mid-2018, John Hulland approached the two of us, asking us to co-edit a JAMS special issue around the general theme of "Innovating in the Digital Economy: Leveraging Technologies to Create Value for Customers and Firms." We agreed to do so, and a call for papers was issued later in the year. In addition, a Thought Leaders' Conference on the same topic was hosted by the Department of Marketing of Bocconi University in Milan, Italy, in mid-2019. The conference was vibrant, participants were deeply engaged, and sessions were highly interactive. Many of the author teams whose work ultimately appears in this special issue participated, and received valuable early feedback on their work. Our thanks to Paolo Guenzi, Gabriele Troilo, Gaia Rubera, Francesca Sotgiu, and Stefan Worm for doing such an excellent job with the organization and execution of that event. In total, almost fifty manuscripts were submitted and considered for inclusion in this special issue.

The conference, and the manuscripts ultimately included in this special issue, brought into focus the new form and focus of innovation in the digital economy. The concept of digital economy has been first articulated by Don Tapscott, who wrote in 1995 that "the Internet and the World Wide Web are enabling a new economy based on the networking of human intelligence." (Tapscott, 1995). Since that time, various definitions of the digital economy have been offered, most centered around the idea of connectivity, and most recently hyperconnectivity, networking, and ecommerce.

In the digital economy, the boundaries of innovation have significantly broadened. Traditionally, innovation has referred primarily to product or service innovation, and to a lesser extent process innovation. Along the same lines, most scholarly

Alina Sorescu

asorescu@mays.tamu.edu

1 Texas A\&M University, College Station, TX, USA

2 WU Vienna University of Economics and Business, Vienna, Austria research has examined product and service innovation (for a review see Hauser et al., 2006), or a more generic form of innovation as captured by the patent activity of firms, or even by their R\&D expenditures (e.g., Jaffe \& Trajtenberg, 2002).

These notions no longer adequately represent the reality of the marketplace. The digital economy encompasses transactions that result from countless online connections among people, businesses, machines and data. These transactions are enabled by technologies that have resulted in process and business model innovations whose design, diffusion, and value appropriation characteristics may not align well with the extant academic knowledge obtained from studying firms in the pre-Internet era. Moreover, hyperconnectivity has also heightened consumers' voice in the design and adoption process, their access to innovation, and the manner in which innovation - for instance the IoT or AI-enabled products and services - shapes their lives. Many aspects of how consumers evaluate and choose innovations in this new environment, and how they access and utilize them, are still understudied. Last but not least, companies are also innovating differently in the digital economy, often leveraging new technologies and big data that allow them to quantify and hone down processes that range from the design to the distribution of innovation.

Current research on innovation should account for the fact that the digital economy has led not only to the advent of new types of innovation, but also to major shifts in the design and the diffusion of innovation, and in how consumers can be engaged by innovation and new technologies. Innovation does not only manifest in what consumers purchase and use, but also in how firms create, deliver, and appropriate value in novel ways. Thus, the purpose of the special issue is to spur thinking on what constitutes innovation in the digital economy and how innovation is changing the behavior of firms, consumers, and society as a whole. While the papers included in this special issue are by no means a comprehensive review of all relevant aspects that pertain to the sources and consequences of innovation in the digital economy, they provide a starting point that we hope will encourage future research. 
With this in mind, we introduce the special issue papers highlighting the types of insights that they provide to this emerging domain, and we propose a few additional research directions that can further build on these papers and advance the marketing literature.

\section{New types of innovation in the digital economy}

It is tempting to consider digital products or online and virtual services as the predominant form of innovation in the digital economy, as they are one of the primary consequences of technology that has allowed us to digitize audio, visual, and textual information. Indeed, from software, music, books, and news available digitally, to services offered virtually, such as telemedicine or tutoring, the digitization of many types of offerings has led to the decline of entire industries (e.g., newspapers) and to the reinvention of others (e.g., music distribution). In marketing, researchers have examined the distribution of these products (digital music, Elberse, 2010), their pricing (digital newspapers, Pattabhiramaiah et al., 2019) and how consumers share them (digital movies, HennigThurau et al., 2007), among others. Yet research in this area is still fragmented and very context focused.

At the same time, there are other forms of innovation that have proliferated in the digital economy. One such category consists of physical products with a digital component (Kindle), or bundles that combine physical products with digital products or services (Alexa). This type of offering has been labeled as "digitalized interactive platform" in recent research (Ramaswamy \& Ozcan, 2018). Digitalized interactive platforms are characterized by ongoing value creation and value delivery, where the user experience is dynamic and potentially co-created by several individuals or entities. There is little, if any evidence in the literature on what characteristics make these offerings successful, how to select partners that enable their value creation and delivery, how to measure their performance, to what extent they offer a competitive advantage, and what is their life cycle.

Related to the digitalized interactive platforms is another category of innovation spurred by technological advances: service innovations enabled by AI, such as robots or chatbots. We had highlighted this type of innovation in the call for papers, as it is increasingly prevalent, but is still understudied. We are excited to see the special issue open with a lead article that provides a comprehensive summary of research in this area to date (Blut et al., 2021). The authors present a metaanalysis that synthesizes data from 11,053 individuals interacting with AI-powered service robots reported in 108 independent samples. Using this data, they develop a model of the antecedents and consequences of anthropomorphism in service settings. Anthropomorphism in their study is defined as the extent to which customers perceive service robots as humanlike. Customer traits and predispositions (e.g., computer anxiety), sociodemographic characteristics (e.g., gender), and robot design features (e.g., physical, nonphysical) are identified as triggers of anthropomorphism. Robot characteristics (e.g., intelligence) and functional characteristics (e.g., usefulness) are identified as important mediators of the relationship between anthropomorphism and intentions to use a robot, whereas robot type (i.e., robot gender) and service type (i.e., possession-processing service, mental stimulusprocessing service) moderate this relationship. Their metaanalysis yields interesting findings highlighting when customers are likely to appreciate anthropomorphism versus when humanlike perceptions might backfire and be negatively related to robot use.

Adding to this body of work is the paper by Hildebrand and Bergner (2021), which focuses on how characteristics of robots, such as their ability to have a conversation, alter consumers' evaluations of financial services firm, and ultimately the manner in which they make financial decisions. In four studies, the authors show that conversational robo-advisors that provide investment advice evoke greater levels of affective trust as opposed to non-conversational interfaces. The core tenet is that AI-enabled chatbots can mimic human-tohuman conversations (e.g., turn-taking) and thereby compensate for the lack of "human touch." These changes in the interface modality in turn led to a more positive firm evaluation, and a more positively-valenced advisory experience for consumers. Moreover, conversational robo-advisors affect both investor perceptions (attributions of affective trust toward the robo-advisor and benevolence of a financial services firm) and investor behavior (asset allocation toward the conversational as opposed to non-conversational robo-advisor in an incentive-compatible investment game). In particular, greater perceptions of affective trust not only affect attributions of benevolence toward the firm but also the likelihood to accept a recommended portfolio, even if this portfolio is inconsistent with consumers' actual risk profile or invokes larger annual management fees. We believe this article holds important substantive implications for the financial service industries and more broadly opens the door to more research on how perceptions of products and firms can be shaped and strengthened by AI-enabled technologies.

Another category of innovations that is increasingly frequent in the marketplace includes process and business model innovations. Business model innovations are defined as a new way of doing things, or, more formally, as a change in the value creation, appropriation, or delivery component of a business model that leads to a substantive increase in the value proposition. This type of innovation appears to drive a majority of new IPO firms, or firms that make it on the unicorn lists of venture capitalists (Foss \& Saebi, 2017). Business model innovation has flourished as new technologies and big data 
have allowed firms to make data driven changes to their processes, and as hyperconnectivity has reshaped their relationships with partners, customers, and consumers at large. Yet empirical research on what factors drive it, and how firms can successfully implement it, is so far only limited to case studies.

\section{The role of innovation in the digital economy}

Extant research on innovation has focused on two of its most prominent roles. For consumers, it provides a potential problem solution that fulfills an existing need or even creates a new need that consumers had not yet articulated (e.g., smartphones). For firms, innovation has been primarily seen as a demand expanding engine of growth. This is in large part because research has focused on the innovation incorporated in the products and services that firms offer to consumers. However, in the digital economy, innovation is not only present in what firms sell, but also in how they sell it. The special issue provides several insights in this area. Specifically, four papers in the special issue explicitly discuss avenues through which firms can better engage customers in the digital economy.

Innovations in the marketing function can increase customer acquisition, facilitate product choice and usage, and increase retention. One of the most exciting developments in customer acquisition pertains to the advancement of geolocation strategies to target customers who are close to an area where they can buy a product in store. However, is something that is technologically feasible also always meaningful from a business perspective? Bernitter, Ketelaar, and Sotgiu (2021) experimentally investigate location-based mobile marketing in the field and find that its effectiveness depends. Specifically, the authors demonstrate that what matters is an effective combination of location targeting (in-store vs. out-store), behavioral targeting (based on consumers' product category involvement), and the type of promotion offered (price vs. nonprice promotion). For example, it is shown that in order to attract consumers to stores by using out-store location-based mobile marketing, firms should offer price promotions to consumers with low product category involvement and non-price promotions to consumers with high product category involvement.

In the same broad domain of customer acquisition, Garnefeld et al. (2021) explore the extent to which product testing results into more favorable online reviews, which, in turn, can attract more customers. Several manufacturers and retailers alike have started to offer to selected customers the opportunity to test products. In case they subsequently write an online review, they can keep the product free of charge. The idea is clear: product testing may serve as a tool to manage online reviews. Using a qualitative study, experimental study, and multilevel analysis of a field study data set of more than 200,000 online reviews by product testers, the authors find that this customer acquisition tool does not always work as intended. Instead, review quality may actually decrease if product testers are asked to write a review after many reviews have already been published about the product. In case of high-priced products, however, the authors confirm our prior beliefs: product testers are effective in yielding favorable reviews and ratings. At the same time, this research is calling into question a widespread practice to give cheaper products away for free in exchange for favorable reviews.

In terms of product choice, Lim et al. (2021) examine how the digital customization of consumer investments improves the risk-returns decisions that these customers make. While digital technology has democratized the finance industry by allowing customers to more easily and more directly invest in many different investment funds (they can bypass financial advisors and customize their own investment portfolio by directly purchasing funds online), this empowerment does not come without risks. In particular, consumers may make suboptimal investment decisions, particularly if the investment decisions involve multiple funds, each of which having a different risk-return distribution. One related challenge for consumers is to optimize risk-returns across funds due to behavioral biases such as mental separation and correlation neglect. The authors build on the insights generated by the literature on mass customization on manufactured products - in particular, the idea that consumers should be equipped with digital toolkits that allow them to experience and test their self-designed creations virtually before the final product is actually purchased (Franke et al., 2010; von Hippel \& Katz, 2002). The authors report a series of three experiments that test whether consumers can benefit from a virtual integration of multiple funds into one combined investment fund; the core idea is to combine the multiple, correlated risk-return distributions into one joint distribution and let customers learn their preferred risk-return levels in an interactive, playful way. In their treatment condition, consumer investors could thus use an interactive tool which ensured an optimal asset allocation between the different investment funds. It is found that virtual integration indeed outperforms separate decision-making for each fund. The effect sizes found are nontrivial and the incremental gains due to virtual integration sizable. Interestingly, financial literacy was not a robust moderator of the effects suggesting that even expert consumers might benefit from the proposed virtual integration of investment funds.

And, finally, from the standpoint of increasing brand awareness, Fossen and Bleier (2021) focus on advertising effectiveness. Specifically, they examine how engaging in conversations about a TV program on social media, while that program is aired, impacts the likelihood that viewers will see the ads presented during the TV programs. Using a dataset of 8417 ad instances, combined with audience size data, and with 
Tweets associated with the programs that the ads air in, the authors show that increases in engagement in social media conversations about television programs (both in terms of volume and in terms of the deviations from the average level of engagement of the program) leads to higher ad audience size. The idea is that such online program engagement proxies viewers' program involvement; the higher that involvement the lower their channel-changing behavior during ads. The authors further provide insight on which ads appear to be more impacted by social media conversations: those ads that air earlier in an ad break.

\section{Antecedents and consequences of innovation in the digital economy}

In the previous two sections we have discussed a broadened view of innovation and of its role. Future research should also re-examine the determinants of innovation in the digital economy, as well as its consequences. More than two decades have passed since classical determinants of innovation output such as market knowledge competence (Li \& Calantone, 1998) or willingness to cannibalize (Chandy \& Tellis, 1998) have been examined. The technological advances and hyperconnectivity that characterize the digital economy are opening up new ways in which firms can compete and new sources of competitive advantage. Responding to this newly established reality, Wielgos et al. (2021) conceptualize and nomologically establish the important concept of digital business capability (DBC), along with determining its impact on firm and customer performance. DBC comprises three complementary capabilities: (1) digital strategy, (2) digital integration, and (3) digital control. The authors show that DBC positively affects customer satisfaction and loyalty, even when controlling for the influence of market orientation. Moreover, DBC pays off at an optimal level of external dynamism and is more valuable for business-to-consumer than for business-to-business firms. Finally, the authors find a marginally significant influence of $\mathrm{DBC}$ on perceived firm innovativeness, a notable behavioral determinant of future engagement with the firm.

Another important source of competitive advantage in the digital economy is the ability to leverage big data in strategy decisions. De Luca et al. (2021) focus on this critical capability and introduce the concept of marketing affordances, which are ways in which technology and big data can be utilized to improve the marketing function. Using data from interviews and multiple surveys with more than 400 managers from two countries, the authors conceptualize and empirically validate three distinct marketing affordances: customer behavior pattern spotting, real-time market responsiveness, and datadriven market ambidexterity. This research, which extends previous work on technological affordances (Lehrer et al., 2018, b), suggests that real-time market responsiveness and data-driven ambidexterity lead to service innovation, but customer behavior pattern spotting does not. Moreover, the authors find that big data marketing affordances relate to perceived big data performance either via service innovation, for real-time market responsiveness and data-driven market ambidexterity, or directly, for customer behavior pattern spotting.

Of course, DBC and the ability to leverage big data are only two examples of capabilities that became relevant in the digital economy. Others could benefit from more scholarly inquiry. In the realm of innovation, one type of capability that has received some research coverage pertains to firms' ability to harness the creativity and insight of external stakeholders during the fuzzy front-end of the innovation process, when ideas are generated for new products. Although research has long suggested that firms might benefit from an active involvement of innovative users into the idea generation process (Poetz and Schreier 2012), it has never been easier to identify such individuals. Instead of trying to find the "right" users with an innovative idea or problem-solution at hand, firms can broadcast their problem in the form of an online crowdsourcing contest to a potentially large and unknown population (Camacho et al. 2019). Firms can either use their own networks and channels (e.g., online communities, social media followers, etc.) or they can tap into farther away populations (e.g., general interest communities, professional crowdsourcing platforms, etc.). Future research can seek to determine the optimal features of such contests and the scope and market value of the innovation that they generate.

Finally, the consequences of innovation have been examined from the standpoint of adoption and diffusion (Peres, Muller and Mahajan 2010) and firm performance (Sood and Tellis 2009; Warren and Sorescu 2017). However, the majority of extant research on innovation outcomes is based on new product introductions. How process and business model innovations, or marketing function innovations diffuse, and what their performance consequences are, is still a nascent area. In this domain, Lamey et al. (2021) investigate the stock market performance of service innovations, including innovations fueled by digital technologies such as electronic shelf labels, smart shopping carts, or electronic fitting tools. This study zooms into contingencies that determine this value, ranging from the customer value benefits (convenience versus engagement products) to the purchase process stage (pre-, during-, and post-purchase) and to the nature of the products offered by the retailer (utilitarian versus hedonic). For instance, the authors find that service innovations that are consistent with the goals of the purchase stage (e.g., helping customers complete the purchase, such as self-scanning, or more streamlined payment or delivery options), are more likely to receive a positive investor reaction. While this study provides a welcome disaggregated view of the valuation of innovation, the extent to which other types of innovations, such as digitized 
interactive platforms or business model innovations, impact firm value, remains a topic for future research.

In sum, the special issue offers an eclectic but insightful collection of articles that, we hope, will provide helpful insights to managers, while continuing to engage researchers into understanding the ever-evolving form, role, and function of innovation in the digital economy. From examining new and special types of innovation, to better understanding its drivers and consequences, the special issue articles propose novel opportunities for the marketing function to better attract, engage and retain customers, while appropriating value for firms' stakeholders and increasing firms' chances of longterm survival and success. We hope that the special issue will spur further interest among researchers to study "the new-normal" and thus help in equipping scholars and students with a holistic and up-to-date knowledge base on how to innovate in an increasingly digitized world.

\section{References}

Bernritter, S., Ketelaar P. \& Sotgiu F. (2021). Behaviorally targeted location-based mobile marketing. Journal of the Academy of Marketing Science, 49(4).

Blut, M., Wang, C., Wünderlich, N. V., \& Brock, C. (2021). Understanding anthropomorphism in service provision: A metaanalysis of physical robots, chatbots, and other AI. Journal of the Academy of Marketing Science, 49(4). https://doi.org/10.1007/ s11747-020-00762-y.

Camacho, N., Hyoryung, N., Kannan, P. K., \& Stremersch, S. (2019). Tournaments to crowdsource innovation: The role of moderator feedback and participation intensity. Journal of Marketing, 83(2), $138-157$.

Chandy, R. K., \& Tellis, G. J. (1998). Organizing for radical product innovation: The overlooked role of willingness to cannibalize. Journal of Marketing Research, 35(4), 474- 487.

De Luca, L. M., Herhausen, D., Troilo, G., \& Rossi, A. (2021). How and when do big data investments pay off? The role of marketing affordances and service innovation. Journal of the Academy of Marketing Science, 49(4). https://doi.org/10.1007/s11747-02000739-x.

Elberse, A. (2010). Bye-bye bundles: The unbundling of music in digital channels. Journal of Marketing, 74(3), 107-123.

Foss, N. J., \& Saebi, T. (2017). Fifteen years of research on business model innovation: How far have we come, and where should we go? Journal of Management, 43(1), 200-227.

Fossen, B. L., \& Bleier, A. (2021). Online program engagement and audience size during television ads. Journal of the Academy of Marketing Science, 49(4). https://doi.org/10.1007/s11747-02100769-z.

Franke, N., Schreier, M., \& Kaiser, U. (2010). The "I designed it myself" effect in mass customization. Management Science, 56(1), 125-140.

Garnefeld, I., Krah, T., Böhm, E., \& Gremler, D. D. (2021). Online reviews generated through product testing: Can more favorable reviews be enticed with free products? Journal of the Academy of Marketing Science, 49(4). https://doi.org/10.1007/s11747-02100770-6.

Hauser, J., Tellis, G. J., \& Griffin, A. (2006). Research on innovation: A review and agenda for marketing science. Marketing Science, 25(6), $687-717$

Hennig-Thurau, T., Henning, V., \& Sattler, H. (2007). Consumer file sharing of motion pictures. Journal of Marketing, 71(4), 1-18.

Hildebrand, C., \& Bergner, A. (2021). Conversational robo advisors as surrogates of trust: Onboarding experience, firm perception, and consumer financial decision making. Journal of the Academy of Marketing Science, 49(4). https://doi.org/10.1007/s11747-02000753-z.

Jaffe, A. B., \& Trajtenberg, M. (2002). Patents, citations, and innovations: A window on the knowledge economy. MIT Press.

Lamey, L., Breugelmans, E., Vuegen, M., \& ter Braak, A. (2021). Retail service innovations and their impact on retailer shareholder value: Evidence from an event study. Journal of the Academy of Marketing Science, 49(4). https://doi.org/10.1007/s11747-021-00777-z.

Lehrer, C., Wieneke, A., vom Brocke, J., Jung, R., \& Seidel, S. (2018). How big data analytics enables service innovation: Materiality, affordance, and the individualization of service. Journal of Management Information Systems, 35(2), 424-460.

Li, T., \& Calantone, R. J. (1998). The impact of market knowledge competence on new product advantage: Conceptualization and empirical examination. Journal of Marketing, 62(4), 13-29.

Lim, S., Donkers, B., van Dijl, P., \& Dellaert, B. C. G. (2021). Digital customization of consumer investments in multiple funds: Virtual integration improves risk-return decisions. Journal of the Academy of Marketing Science, 49(4). https://doi.org/10.1007/s11747-02000740-4.

Pattabhiramaiah, A., Sriram, S., \& Manchanda, P. (2019). Paywalls: Monetizing online content. Journal of Marketing, 83(2), 19-36.

Peres, R., Muller, E., \& Mahajan, V. (2010). Innovation diffusion and new product growth models: A critical review and research directions. International Journal of Research in Marketing, 27(2), 91106.

Poetz, M. K., \& Schreier, M. (2012). The value of crowdsourcing: Can users really compete with professionals in generating new product ideas? Journal of Product Innovation Management, 29(2), 245-256.

Ramaswamy, V., \& Ozcan, K. (2018). Offerings as digitalized interactive platforms: A conceptual framework and implications. Journal of Marketing, 82(4), 19-31.

Sood, A., \& Tellis, G. J. (2009). Do innovations really pay off? Total stock market returns to innovation. Marketing Science, 28(3), 442456.

Tapscott, D. (1995). Digital economy. Promise and peril in the age of networked intelligence. McGraw-Hill.

von Hippel, E., \& Katz, R. (2002). Shifting innovation to users via toolkits. Management Science, 48(7), 821-833.

Warren, N. L., \& Sorescu, A. (2017). Interpreting the stock returns to new product announcements: How the past shapes investors' expectations of the future. Journal of Marketing Research, 54(5), 799-815.

Wielgos, D. M., Homburg, C., \& Kuehnl, C. (2021). Digital business capability: Its impact on firm and customer performance. Journal of the Academy of Marketing Science, 49(4). https://doi.org/10. 1007/s11747-021-00771-5.

Publisher's note Springer Nature remains neutral with regard to jurisdictional claims in published maps and institutional affiliations. 